Article

\title{
Efficiency Comparison of AC and DC Distribution Networks for Modern Residential Localities
}

\author{
Hasan Erteza Gelani ${ }^{1, *}$, Faizan Dastgeer ${ }^{1}\left(\mathbb{D}\right.$, Kiran Siraj $^{2}$, Mashood Nasir ${ }^{2} * \mathbb{( D}$, \\ Kamran Ali Khan Niazi ${ }^{3}$ D and Yongheng Yang ${ }^{3}(\mathbb{D}$ \\ 1 Electrical Engineering Department, University of Engineering and Technology Lahore, 38000 Faisalabad \\ Campus, Pakistan; faizandastgeer@uet.edu.pk \\ 2 Electrical Engineering Department, SBASSE, Lahore University of Management Sciences, 54792 Lahore, \\ Pakistan; 16060040@lums.edu.pk \\ 3 Department of Energy Technology, Aalborg University, 9100 Aalborg, Denmark; kkn@et.aau.dk (K.A.K.N.); \\ yoy@et.aau.dk (Y.Y.) \\ * Correspondence: erteza.gelani@uet.edu.pk (H.E.G.); mashood.nasir@lums.edu.pk (M.N.); \\ Tel.: +92-3214894565 (H.E.G.); +92-3336313145 (M.N.)
}

Received: 15 January 2019; Accepted: 5 February 2019; Published: 11 February 2019

check for updates

\begin{abstract}
The paper investigates the system efficiency for power distribution in residential localities considering daily load variations. Relevant system modeling is presented. A mathematical model is devised, which is based on the data from the Energy Information Administration (EIA), USA, for analysis. The results reveal that the DC distribution system can present an equivalent or even better efficiency compared to the AC distribution network with an efficiency advantage of $2.3 \%$, averaged over a day. Furthermore, the distribution systems are compared under various capacities of solar PV accounting for the effect of variation in solar irradiation over time.
\end{abstract}

Keywords: efficiency; DC distribution; DC vs. AC; daily load variation; residential; solar; capacity

\section{Introduction}

The electric power system started with a battle between two paradigms of AC and DC for power transfer towards the end of the nineteenth century. The earliest power system was DC in nature and AC won the confrontation due to its ability of voltage level transformation [1,2]. Evidently, if DC had this property at that time, the power system could have been DC in nature. AC developed this property with the invention of electromagnetic transformers. AC enjoyed its rule over all the major stages (generation, transmission, distribution, and utilization) of the power system. DC could not develop a significant presence at that time and was left with dwarfish importance [3].

AC had a pleasant time of command over the power system until the evolution of High Voltage Direct Current (HVDC) transmission, which was proven better as compared to High Voltage Alternating Current (HVAC) transmission with profuse successful installations [4], bringing DC back to the picture of the power system. Generation was a strong ally of $\mathrm{AC}$ with three-phase synchronous alternators. DC made its move with the trending renewable energy technologies, threatening AC at the generation end. The solar PV generates DC power; wind farms have a topology, which produces DC at an intermediate stage for conversion to stable and synchronized AC output [5]. Advancement in power electronics enables both conversions between AC and DC as well as voltage level transformation. The power output from solar/wind can effectively be converted to AC for AC dependent loads with power converters [6,7]. It would not be an exaggeration that power electronics have formed a base for DC to stand on and compete against AC. At the utilization end, the stupendous inflation of modern electronic loads had brought notable demand for DC. The shifting trend towards LED lights, 
electronics, mobile phone and laptop chargers in the modern home adds to the DC side, strengthening it further as compared to AC [8]. Moreover, lower line losses, lower voltage dips and simplified control associated with the low voltage DC distribution (LVDC) systems have made it an optimal choice for low-cost rural electrification [9-14].

Figure 1 depicts the penetration of DC in the power system. DC has set up concrete grounds in generation, transmission, and utilization, while distribution is the portion that is still under the research phase. Various aspects of DC in distribution still need to be brought to light. The entire shift towards DC cannot be realized without resolving the technical challenges associated with the emerging DC power systems. These challenges mainly include space charge accumulation in DC cable insulation [15], DC system protection [16], and DC system stability [17]. It should be noted that DC breakers are more sophisticated and cumbersome to manage in the case of short-circuits or unwanted transients. For instance, during a system fault and associated opening of the circuit breakers, the arcing is largely limited in AC due to the zero crossing unlike the case of DC, where forced commutation or energy chopping devices have to be installed to dissipate the arc energy. In DC systems these arcs may be higher and could potentially be hazardous [16]. The existing era is, therefore, witnessing the reignited battle of currents with both the competitors, AC and DC, having their advantages and disadvantages, and thereby motivating the researchers to explore the various factors for comparative analysis.

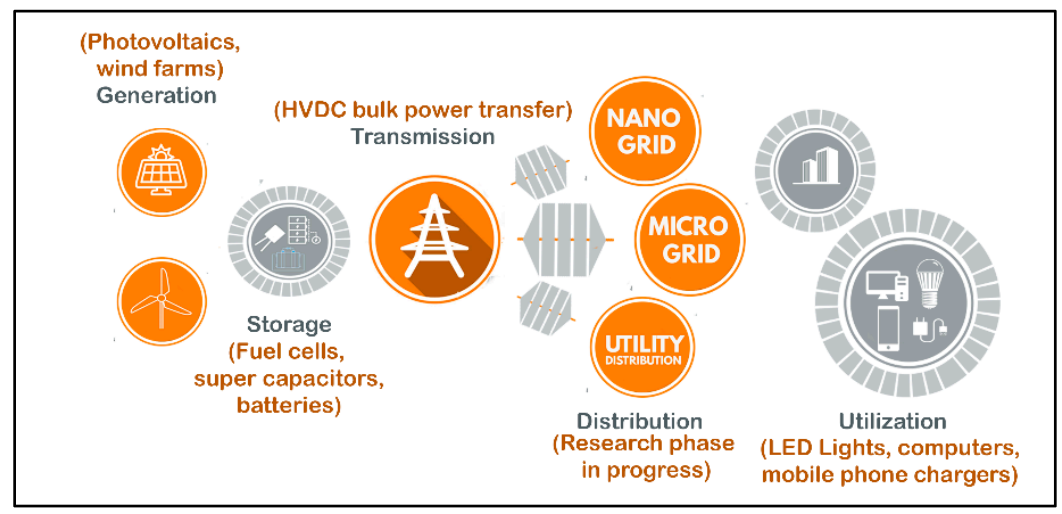

Figure 1. DC in the Power System.

Comparison of AC and DC distribution is the subject of many researchers. For instance, the authors of [18] presented a small-scale network for comparison of AC and DC distribution. They concluded that input savings of $7 \%$ can be achieved with DC distribution at $400 \mathrm{~V}$. In [19], the authors presented that conduction losses of DC are 37\% of the AC system. Furthermore, [20] presented the loss comparison of DC distribution for two voltage levels ( $24 \mathrm{~V}$ and $48 \mathrm{~V})$, where it was concluded that the DC system with $48 \mathrm{~V}$ should be a better choice. However, load variation was not considered for this study. The authors of [21] discussed the comparison of AC and DC systems with the inclusion of solar PV. They concluded that the DC system utilized solar energy was better than the AC system. However, the loads under consideration were LED lights with single power electronic converter as a driver. The author of [22] concluded from the comparison of AC and DC that if local generation is provided, only DC is a suitable option. The work presented in [23] was another efficiency comparison of the two paradigms. The study revealed that DC-DC converter efficiency as the defining factor for AC and DC systems' efficiencies. The loads were divided on a 50-50 basis, i.e., half loads as AC and half $\mathrm{DC}$, and the effect of power electronic inter-conversions (AC/DC, DC/AC) was not included.

Across the globe, DC power is assumed to have not gained significant fame as compared to AC power in the residential sector $[3,24,25]$. This paper aims to present the viability of DC at the residential level, by presenting a comparative analysis of AC and DC distribution networks. Several factors influence the comparison; however, this study frames the factor of "time". This reflects how the power demands of loads installed within the home change through a day. Power electronic 
converters form the backbone of DC distribution systems. With changing load demand, the efficiencies of the installed power electronic converter change. Thus, a time-based study considering daily load variation and efficiency variation of converters with changing loads is important to perform a comparative analysis. In this study, average load data for a standard US home is used for the purpose of analysis. A mathematical model of the systems is formulated at an hourly basis. MATLAB is used for mathematical model-based calculations and analysis. The focus of this study is to keep the comparison fair; therefore, the conditions for both the systems are kept similar so that a real picture is obtained that portrays actual comparison in the time frame.

\section{Comparison with Previous Research}

DC distribution has been the subject of [26,27], but their work lacks comparison of AC and DC at the distribution level. However, the theme of current research is on the comparison of AC and DC distribution systems. The authors of [28] have focused on commercial buildings with DC loads and assumed DC as an available medium of power, where the conversion stages and associated losses were ignored. This research is solely focusing on residential localities and highlighting the effect of converter efficiencies on residential distribution networks. The work presented in [29] assumes that all loads in residence are inherently DC. In contrast to the prior-art research, this paper offers work based on practical load data, containing both AC and DC loads that exist in a typical residential building. [8,30] are two of our earlier studies on DC power distribution. In [30], we presented the efficiency analysis of DC distribution system but did not carry out its comparison with AC distribution system. Furthermore, the power consumed by loads was arbitrarily divided into three-time zones constituting a day. However, in the current work, a typical hourly consumption of loads is utilized to derive a comparison of $\mathrm{AC}$ and DC distribution systems. In [8], we took variable converter efficiencies without considering load variation, whereas the theme of the current effort is based on changing efficiencies of converters with loading. The authors of [23] presented the comparison of both distribution schemes with quite high values of converter efficiencies (up to 99.5\%); the authors themselves claimed that such high-value converters are quite rare. A time-based study is missing in [31], where the authors have presented DC distribution, its efficiency analysis and comparison with AC counterpart with certain assumptions. In addition to the comparison of $A C$ and DC distribution networks considering daily load variation based on actual data, this research effort features the study of the effect of solar irradiance variations throughout the day on DC and AC distribution systems. In the past, studies have been presented with solar PVs in the DC distribution due to the shifting trend towards renewable resources, i.e., $[13,28]$. However, the authors of both research efforts in $[13,28]$ did not compare AC and DC distribution at the residential level considering hourly load as well as solar irradiance variations.

\section{In-building System Model}

The system modeling presented here finds its basis in the Buildings Energy Databook [32], which presents end-use splits of US residential energy consumption. Subsequently, the residential loads are broadly classified into three categories; ' $A$ ', ' $D$ ' and ' $I$ ', as explained in the following:

' $A$ ' category: The loads that are inherently AC in nature. Examples include induction motor-base clothes washer and compressors in refrigerators and air-conditioners. In a DC distribution system, these will require a DC-AC conversion stage for operation, whereas the AC distribution system, they will be directly operated from the power mains.

' $D$ ' category: The loads that can operate on DC fall in this category. Lighting, due to the advent of LEDs, falls in this category. Home electronics, computers, and laptops are other examples of D category loads. These loads require AC-DC conversion in the AC system and DC-DC conversion in the DC system for stepping down the mains DC voltage to a level essential for the loads. 
' $I$ ' category: The loads independent of the type of power available fall in this category. Heating loads, e.g., electric iron and water heaters, fall in this category. These do not require a conversion stage for their operation and can directly be operated from the power mains if a suitable voltage is supplied.

The average monthly consumption of a US home [33] is considered for modeling. This allows us the analysis of single/multi-family homes through a single platform. The average monthly consumption of a US home is $911 \mathrm{kWh}$, which gives average daily consumption of about $30 \mathrm{kWh}$. The energy data are combined with this value to give the kWh-of-energy consumed by each load. Table 1 presents the residential energy splits and energy in $\mathrm{kWh}$ for each load. The percentage consumption in $24 \mathrm{~h}$ is calculated for each load, as depicted in the pie chart. This value is combined with the average daily consumption to form 'Energy kWh' column. For example, water heating accounts for 0.48/4.795 of the total home's consumption. Combining this ratio with the average daily consumption of $30 \mathrm{kWh}$ gives $2.64 \mathrm{kWh}$ of the energy consumed per day. Furthermore, loads are categorized into ' $\mathrm{A}^{\prime}$, ' $\mathrm{D}$ ' and ' $\mathrm{I}$ ' categories, as explained in the above; 'other' load type is given an equal share in each category. For mathematical modeling/simulation and analysis, the MATLAB software is used.

Table 1. Residential Energy Splits.

\begin{tabular}{cccccc}
\hline Sr. No & Load Type & $\begin{array}{c}\text { Energy (Quadrillion } \\
\text { British Thermal Units) }\end{array}$ & $\begin{array}{c}\text { Percentage } \\
\text { Energy (\%) }\end{array}$ & $\begin{array}{c}\text { Energy } \\
(\mathbf{k W h})\end{array}$ & $\begin{array}{c}\text { Category } \\
(\mathbf{A}, \mathbf{D}, \mathbf{I})\end{array}$ \\
\hline 1 & $\begin{array}{c}\text { Heating } \\
(\text { Space) }\end{array}$ & 0.42 & 8.78 & 2.64 & $\mathrm{I}$ \\
\hline 2 & $\begin{array}{c}\text { Water } \\
\text { Heater }\end{array}$ & 0.48 & 9.93 & 2.98 & $\mathrm{I}$ \\
\hline 3 & $\begin{array}{c}\text { Cooling } \\
\text { (Space) }\end{array}$ & 1.02 & 21.14 & 6.37 & $\mathrm{~A}$ \\
\hline 4 & Lights & 0.53 & 11.04 & 3.31 & $\mathrm{D}$ \\
\hline 5 & Refrigerator & 0.45 & 9.45 & 2.84 & $\mathrm{~A}$ \\
\hline 6 & Electronics & 0.33 & 6.86 & 2.06 & $\mathrm{D}$ \\
\hline 7 & Cleaning & 0.33 & 6.8 & 2.04 & $\mathrm{~A}$ \\
\hline 8 & Cooking & 0.11 & 2.36 & 0.71 & $\mathrm{I}$ \\
\hline 9 & Computers & 0.19 & 3.95 & 1.19 & $\mathrm{D}$ \\
\hline 10 & Others & 0.94 & 19.69 & 5.91 & $0.33 \mathrm{~A}+0.33 \mathrm{D}+0.33 \mathrm{I}$ \\
\hline 11 & Total & 4.795 & 100 & 30.03 & \\
\hline
\end{tabular}

The next step is to find the energy consumption of each load per hour. For this, we refer to the curves from the Energy Information Administration (EIA) for each load type [33]. From the curves, we were able to acquire the hourly distribution of energy of each load, as shown in Figure A1. For example, the overall consumption of space heating is $2.64 \mathrm{kWh}$, and then we fitted this value in the curve equation gained from MATLAB curve fitting tool and obtained the consumption value for each hour. After performing a similar task for each load type except for the "other" load type, which is allotted the equal share in each hour, Table 2 was formulated. 
Table 2. Hourly Power Consumption of 'A', 'D' and 'I' Category Loads in Watts (W) from 00:00 to 24:00.

\begin{tabular}{|c|c|c|c|c|c|c|c|c|c|c|c|c|c|c|c|c|c|c|c|c|c|c|c|c|}
\hline Space Cooling & 183.75 & 183.75 & 122.50 & 61.250 & 0 & 0 & 0 & 0 & 0 & 0 & 61.250 & 61.250 & 122.50 & 183.8 & 245 & 306.25 & 428.75 & 735 & 796.25 & 735 & 673.8 & 612.5 & 551.3 & 306.3 \\
\hline Wet Cleaning & 113.6 & 113.6 & 109.813 & 107.288 & 107.288 & 108.551 & 108.551 & 109.813 & 112.338 & 113.6 & 114.862 & 116.124 & 119.911 & 121.2 & 124.96 & 126.222 & 127.485 & 128.746 & 131.271 & 130.008 & 127.5 & 126.3 & 121.2 & 119.9 \\
\hline Refrigeration & 35.365 & 35.365 & 16.752 & 14.891 & 35.365 & 37.226 & 44.6715 & 74.4525 & 83.7591 & 111.679 & 115.401 & 115.401 & 113.540 & 113.5 & 111.679 & 109.817 & 102.372 & 107.956 & 111.678 & 113.540 & 113.5 & 111.7 & 107.9 & 102.4 \\
\hline Others & 81.810 & 81.810 & 81.810 & 81.810 & 81.810 & 81.810 & 81.810 & 81.810 & 81.810 & 81.810 & 81.810 & 81.810 & 81.810 & 81.81 & 81.810 & 81.810 & 81.810 & 81.810 & 81.810 & 81.810 & 81.81 & 81.81 & 81.81 & 81.81 \\
\hline Computer & 164.954 & 164.954 & 164.954 & 158.4 & 151.85 & 140.92 & 103.779 & 102.69 & 103.78 & 114.703 & 125.63 & 131.09 & 131.09 & 131.1 & 131.09 & 131.09 & 131.09 & 131.09 & 131.09 & 122.35 & 147.5 & 162.2 & 164.9 & 167.7 \\
\hline Lighting & 47.670 & 47.670 & 47.670 & 47.670 & 47.670 & 47.670 & 47.670 & 47.670 & 47.670 & 49.309 & $\begin{array}{l}55.884 \\
\end{array}$ & 57.528 & 49.309 & 49.31 & 49.309 & 54.2403 & 55.884 & 52.597 & 49.3094 & 47.670 & 47.67 & 47.67 & 47.67 & 47.67 \\
\hline Electronics & 82.68 & 82.68 & 84.054 & 82.68 & 82.68 & 82.66 & 82.68 & 84.054 & 85.431 & 96.455 & 99.2107 & 89.565 & 82.68 & 85.43 & 89.565 & 96.455 & 89.565 & 85.431 & 82.68 & 82.68 & 82.68 & 82.68 & 82.68 & 82.68 \\
\hline Others & 81.810 & 81.810 & 81.810 & 81.810 & 81.810 & 81.810 & 81.810 & 81.810 & 81.810 & 81.810 & 81.810 & 81.810 & 81.810 & 81.81 & 81.810 & 81.810 & 81.810 & 81.810 & 81.810 & 81.810 & 81.81 & 81.81 & 81.81 & 81.81 \\
\hline Water Heating & 73.8326 & 73.8326 & 60.7699 & 56.7943 & 73.833 & 90.871 & 119.268 & 159.024 & 193.101 & 204.46 & 170.383 & 141.985 & 130.627 & 119.3 & 119.268 & 122.11 & 130.627 & 159.024 & 167.543 & 141.99 & 119.3 & 119.3 & 119.3 & 113.6 \\
\hline Space Heating & 91 & 83 & 80 & 82 & 87 & 89 & 85 & 105 & 101 & 103 & 101 & 100 & 100 & 98 & 97 & 112 & 145 & 150 & 157 & 158 & 150 & 137 & 122 & 107 \\
\hline Cooking & 0 & 0 & 0 & 0 & 0 & 14.2 & 21.3 & 63.9 & 85.2 & 35.5 & 21.3 & 14.2 & 71 & 85 & 35.5 & 14.2 & 7.1 & 21.3 & 49.7 & 78.1 & 71 & 14 & 7.1 & 0 \\
\hline Others & 81.810 & 81.810 & 81.810 & 81.810 & 81.810 & 81.810 & 81.810 & 81.810 & 81.810 & 81.810 & 81.810 & 81.810 & 81.810 & 81.81 & 81.810 & 81.810 & 81.810 & 81.810 & 81.810 & 81.810 & 81.81 & 81.81 & 81.81 & 81.81 \\
\hline
\end{tabular}




\section{Mathematical Model}

The entries of Table 2 form a matrix with 24 columns representing hours of the day and 12 rows representing loads in a typical modern home. The entries of the matrix are the power consumption per hour of each load.

$$
X_{i, j}=\left[\begin{array}{cccc}
x_{1,1} & x_{1,2} & \ldots & x_{1,24} \\
x_{2,1} & x_{2,2} & \ldots & x_{2,24} \\
x_{n 1,1} & x_{n 1,2} & \ldots & x_{n 1,24} \\
\vdots & . & \ldots & \vdots \\
x_{n 3,1} & x_{n 3,2} & \cdots & x_{n 3,24}
\end{array}\right] \in \mathbb{R}^{i * j}
$$

where the power consumption of ' $\mathrm{A}$ ' category loads is taken from $x_{1}$ to $x_{n 1}$. Similarly, the power consumption of ' $\mathrm{D}$ ' category loads is taken from $x_{n 1+1}$ to $x_{n 2}$, and 'I' category from $x_{n 2+1}$ to $x_{n 3}$. Here, ' $j$ ' defines hours of the day, from 1 to 24 .

In order to find the rating of the appropriate converter for the power/voltage level conversion, we need to find the maximum load that needs to be supplied by the converter. The maximum value of power consumption of load can be found from

$$
Y(i, 1)=\max _{o f}\left(x_{i, j}\right)
$$

where ' $Y$ ' takes the maximum values of all the entries of $X_{i, j}$ representing power consumptions of loads for each hour. A margin of $20 \%$ is further added to the maximum value of load consumption for practical reasons as

$$
R(i)=1.2 \times Y^{T}
$$

The matrix is transposed to convert the column matrix formed in (2) to the row matrix for ease of calculations.

The next step is to find the percentage loading. This value is important because it is utilized to find the operating efficiency of the converter. A matrix with the similar dimensions as $X_{i, j}$ can be created

$$
P_{i, j}=\frac{100 \times x_{i, j}}{R(i)}
$$

For ' $A$ ' category loads:

The percentage loading is placed in a curve equation of the DC-AC converter that gives the efficiency of converter for each hour. A general equation may be

$$
\eta_{i, j}=f(l) ; i=1 \rightarrow n 1 \text { and } j=1 \rightarrow 24
$$

where ' $\eta$ ' is the efficiency of the DC-AC converter as a function of percentage loading ' $l$ '. In (5), the efficiency of the converter is the function of percentage loading. The curves and their corresponding equations are presented in the subsequent section.

For ' $D$ ' category loads:

Similarly, the percentage loading is placed in the curve equation of the DC-AC converter, which gives the efficiency of converter for each hour. The same equation as (5), with required modifications, can be derived for converters driving ' $\mathrm{D}$ ' category loads.

$$
\eta_{i, j}=f(l) ; i=n 1+1 \rightarrow n 2 \text { and } j=1 \rightarrow 24
$$

For 'D' Category loads:

There is no need for a conversion stage. Hence, the conversion efficiency is given as 


$$
\eta_{i, j}=100 \% ; i=n 2+1 \rightarrow n 3 \text { and } j=1 \rightarrow 24
$$

To acquire the input matrix, we made use of the general formula of efficiency that equals $100 \%$ of output/input, which is depicted as

$$
\mathrm{Xin}_{i, j}=\frac{X_{i, j}}{\eta_{i, j}} \times 100 \%
$$

which contains the input power to a residential building for $24 \mathrm{~h}$. The efficiency matrix is formed by combining (5)-(7), and the output matrix is the one formed in (1).

All the entries of the input power matrix are added to give the total input to the building per hour as

$$
X i n_{j}=\sum_{i=1}^{n 1} X i n_{i, j}+\sum_{i=n 1+1}^{n 2} X i n_{i, j}+\sum_{i=n 2+1}^{n 3} X i n_{i, j}
$$

Similarly, the loadings of each home in each hour can be formed as

$$
X_{j}=\sum_{i=1}^{n 1} X_{i, j}+\sum_{i=n 1+1}^{n 2} X_{i, j}+\sum_{i=n 2+1}^{n 3} X_{i, j}
$$

The overall efficiency of a building per hour can be computed by

$$
\eta_{B B}=\frac{X_{j}}{X i n_{j}} \times 100 \%
$$

Suppose that we have a system with ' $m$ ' buildings per DC-DC converter transformer (DC, XFMR) in a residential community. We can adopt the same procedure for the overall efficiency of the system as we did for one building. The output of each DC-DC converter transformer is the input to ' $\mathrm{m}$ ' buildings, which can be expressed as

$$
X_{D C, X F M R}=m \times X_{i n}
$$

For the DC-DC converter transformer, (2) and (3) can be utilized to find the ratings given by

$$
R_{D C, X F M R}=1.2 \times \max X_{D C, X F M R_{j}}
$$

In order to find the percentage loading of the DC-DC converter transformer in each hour, the load on DC-DC converter transformer is divided by its rating as

$$
P_{D C, X F M R_{j}}=\frac{X_{D C, X F M R_{j}}}{R_{D C, X F M R}}
$$

Subsequently, (5) can be utilized to acquire the efficiency for ' $\mathrm{m}$ ' number of buildings as

$$
\eta_{i, j}=f(l) ; i=1 \rightarrow m \text { and } j=1 \rightarrow 24
$$

The overall system input is the power delivered by the grid, which forms the DC-DC converter tansformer's input. This can be found in

$$
X_{D C, X F M R, i n_{j}}=\frac{X_{D C, X F M R_{j}}}{\eta_{D C, X F M R_{i, j}}} \times 100 \%
$$

The values for multiple DC-DC converter transformers are combined to produce the power from the grid, which is taken as the system input for each hour. The output of the system per hour is the hourly power consumption of all the loads combined as shown in (1). The ratio of (1) and (16) gives the overall system's efficiency. 
The same procedure is employed to determine the AC system's efficiency. However, in the case of $\mathrm{AC}$, 'A' and 'I' category loads are operated directly online, whereas the AC-DC converter is employed for driving D category loads. Moreover, in place of the DC-DC converter transformer, a distribution transformer is employed. The working efficiencies of AC-DC converters and the transformers can be determined by making the use of (5) with appropriate changes.

\section{Overall System Model and Analysis}

An overall picture of the system model is depicted in Figure 2. The left side represents a DC distribution system. The 11-kV primary distribution lines are depicted in red and black. DC-DC converter transformers are employed for the primary DC-DC conversion, which steps down the voltage level from $11-\mathrm{kV}$ to $325-\mathrm{V}$. From each DC-DC Converter transformer, $325-\mathrm{V}$ power lines are drawn to energize the buildings. The in-building " $\mathrm{A}, \mathrm{D}, \mathrm{I}$ " loads are powered through converters where required. ' $A$ ' category loads are driven through inverters that convert $325-\mathrm{V}$ DC to $230-\mathrm{V} A C$. Since ' $\mathrm{D}$ ' category loads are small devices, they require power at a lower voltage level. Therefore, they are driven through DC-DC converters that convert 325-V DC to 24-V DC. 'I' category loads being independent are driven directly through the service mains.

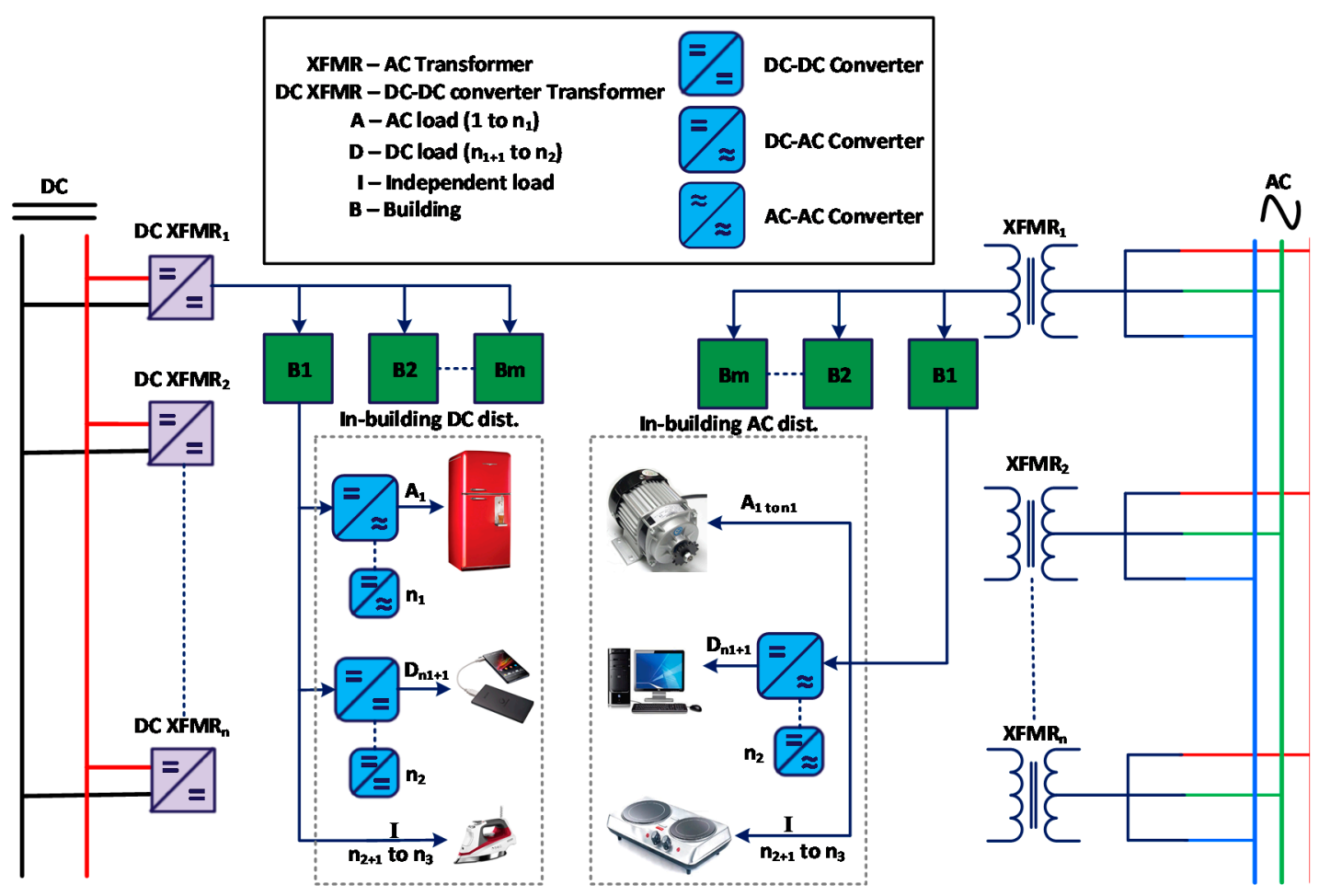

Figure 2. Overall system model.

The right side of Figure 2 is the AC analogous to the left side. Three-phase lines run from the $11-\mathrm{kV}$ grid. The transformers perform their duty of voltage transformation to $230-\mathrm{V}$ per phase. Power at this voltage level is brought to the building, where it is converted to DC via AC-DC converter to drive ' $\mathrm{D}$ ' category loads. In contrast, category ' $\mathrm{A}$ ' and ' $\mathrm{I}$ ' category loads directly run on $230-\mathrm{V}$ available at the service mains. For analysis, the system voltage at the primary distribution voltage level is chosen to be $11-\mathrm{kV}$ for both $\mathrm{AC}$ and $\mathrm{DC}$ systems. Secondary distribution is performed at $230-\mathrm{V}$ per phase for the AC system and 325-V for DC system. The purpose of choosing these voltage levels draws support from [30]. We assumed a system of 63 buildings. For distribution, 21 buildings are assumed; hence, in total3 DC-DC converter transformers are employed. For the AC system, since there are three conductors per phase, each conductor is assumed to supply 7 buildings. The figure 
presents a conceptual diagram of the two systems. We have chosen "Hare" aluminum conductor steel reinforced (ACSR) for both (AC and DC) distribution networks and spacing of $300 \mathrm{~m}$ between distribution transformers is assumed. The physical systems of AC and DC distribution draw their support from [8]. Conductor losses are almost comparable at the secondary distribution level, therefore neglected. At the primary distribution level, DC resistance of a conductor is accounted in the DC system analysis, whereas, AC, as well as DC resistances, are accounted in the AC system analysis. Moreover, the power factor of $\mathrm{AC}$ loads and the loss associated with the power factor is also considered in the analysis of the AC system.

The input data are acquired through a bottom-up approach using the mathematical model discussed in the previous section. The 'loading vs. efficiency' curves of converters along with their equations (acquired from MATLAB curve-fitting tool) are presented in Figure 3 and (17), respectively. The curve-fitting tool provides a function that fits the curve data, and then approximate results can be obtained by increasing the degree of the function.

$$
\eta(l)=\sum_{i=0}^{j} k_{i} \times(l-10 i) \times u(l-10 i)
$$

where " $\eta$ " is the efficiency of converter as a function of percentage loading ' $l$ ', moreover,

For DC-DC converters, $j=8$ and the corresponding values of $k$ are:

$k_{0}=8.1, k_{1}=-7.05, k_{2}=-0.625, k_{3}=-0.25, k_{4}=-0.2, k_{5}=-0.05, k_{6}=0.05, k_{7}=0, k_{8}=-0.0125$

For AC-DC converters, $j=9$ and the corresponding values of $k$ are:

$k_{0}=9.15, k_{1}=-8,785, k_{2}=-0.23, k_{3}=-0.075, k_{4}=-0.02, k_{5}=-0.03, k_{6}=0, k_{7}=0, k_{8}=-0.018$, $k_{9}=-0.004$

For DC-AC converters, $j=9$ and the corresponding values of $k$ are:

$k_{0}=7.52, k_{1}=-6.74, k_{2}=-0.48, k_{3}=-0.1, k_{4}=-0.09, k_{5}=-0.07, k_{6}=-0.06, k_{7}=0.05, k_{8}=-0.01$, $k_{9}=-0.01$

For AC-AC transformers, $j=7$ and the corresponding values of $k$ are:

$k_{0}=9.47, k_{1}=-9.24, k_{2}=-0.15, k_{3}=-0.06, k_{4}=-0.01, k_{5}=-0.01, k_{6}=-0.01, k_{7}=0.005$
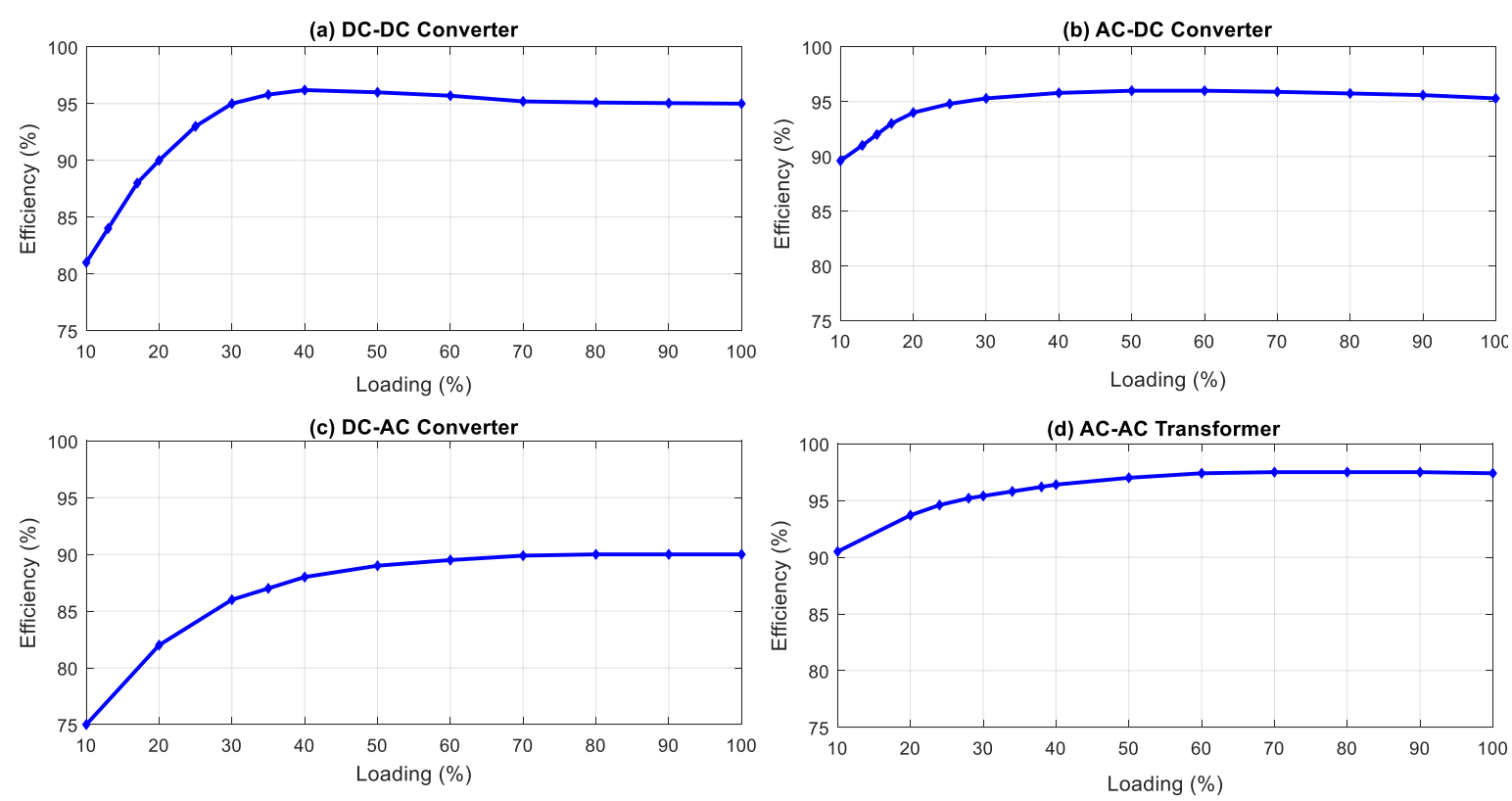

Figure 3. Loading vs. efficiency curves of (a) DC-DC converters [34], (b) AC-DC converters [35], (c) DC-AC converters [36], and (d) AC-AC transformers [37]. 
The mathematical model and data from Table 2 are combined for converter efficiencies against loading using the above expressions resulting in the efficiency comparison of $\mathrm{AC}$ and DC distribution systems presented in Figure 4. The comparison of AC and DC home is also presented in Figure A2.

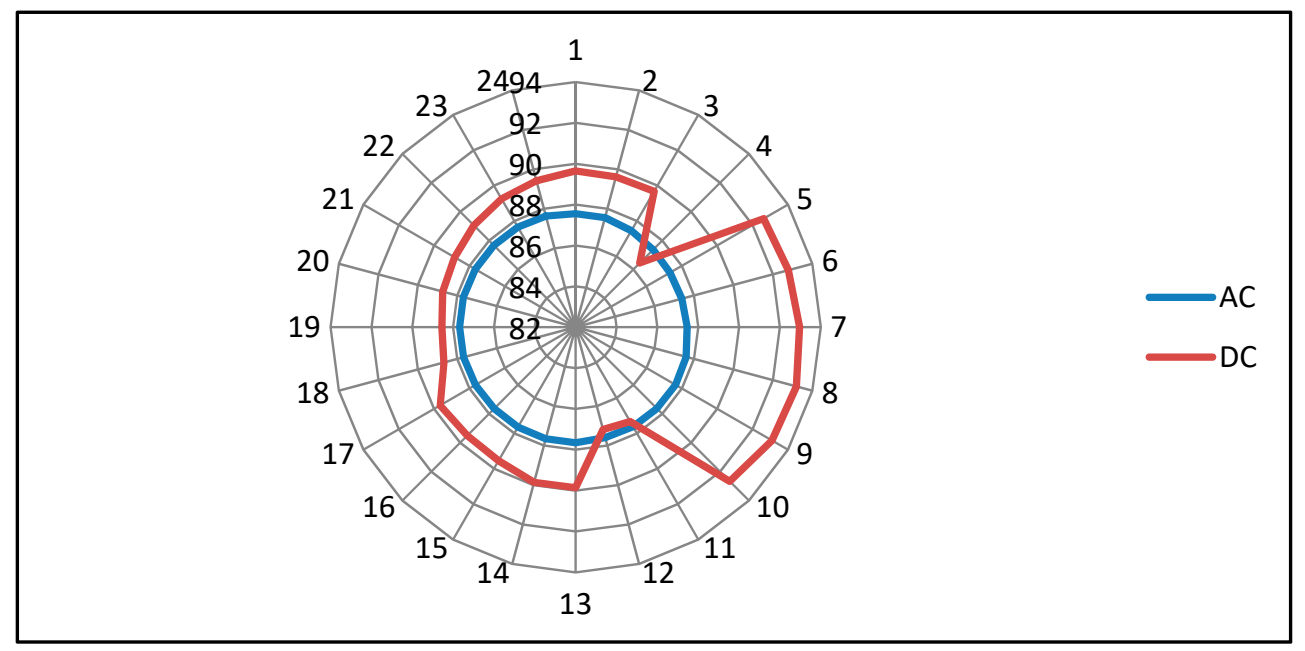

Figure 4. System efficiency for $24 \mathrm{~h}$ of the AC and DC system.

\section{Discussion}

- Drop in DC system efficiency at 4th hour:

The reason is that ' $A$ ' category loads operate at lower loading that causes connected inverters' efficiency to reduce. The effect can also be seen in the building's efficiency graph. The building's efficiency drops in this period and the effect is shifted to the system's efficiency as well.

- The DC curve remains almost constant from the 5th to 10th hour with fair DC efficiency values:

The ' $\mathrm{D}$ ' and ' $\mathrm{A}$ ' category loads operate at an almost constant level in a combined fashion. While DC-DC converters operate at lower efficiency, DC-AC converters operated at higher efficiency and vice versa, keeping overall efficiency constant.

- Drop in the DC efficiency during the 11th and 12th hour:

Again, due to the reduced loading of inverters, 'A' category loads operate at lower efficiency of converters and the effect is pronounced at the DC-DC converter transformer level and in turn the grid level, lowering the overall efficiency of the system

- DC efficiency improved at the 13th hour and onwards:

The reason is the same as that for the 4th to 9th hour. The loads operate in coordination, and the loads consuming more power with converters operating at higher efficiency balance the loads consuming less power with converters operating at lower efficiency.

- Average efficiency

Apparently, DC shows dominance in the comparative graph for the most part of the day. The average efficiencies of both the systems are separated by an amount of almost $2 \%$ with the DC system operating at $89.9 \%$ and $\mathrm{AC}$ system at $87.6 \%$ in Figure 4 .

\subsection{Effect of Residential Solar PVs on Systems Efficiencies}

There is a worldwide focus on the installation of clean, green and environmentally friendly renewable energy resources. In line with the argument, we employed solar PV panels on rooftops of homes and studied the power efficiency comparison of the two paradigms, i.e., AC and DC distribution 
systems. The topological designs of the two remained the same in this part of the analysis with a slight modification of supplying ' $\mathrm{D}$ ' and 'I' category loads with solar PV panels.

The idea is to supply ' $\mathrm{D}$ ' and ' $\mathrm{I}$ ' category loads with a 1-kW solar system on the rooftop, accompanied with the maximum power point tracking (MPPT) converter and a battery bank, and study the comparative analysis of both AC and DC distribution systems. The priority scheme is as follows. When solar energy is available, loads are driven via solar and extra power is used to charge the battery bank. During the periods when solar energy is insufficient to drive loads, the rest of the power shall be taken from the battery storage. When both solar and battery power are insufficient, power is taken from the utility to drive the loads. In order to fit solar in the mathematical model, the solar irradiance data curve [38] was utilized, as shown in Figure A3. The expression for solar power against hours of the day was fitted in the mathematical model for analysis of solar inclusion on the system's efficiencies. The solar power can be given as

$$
P(t)=0.969 e^{\frac{-(t-12.24)}{3.075^{2}}}+0.403 e^{\frac{-(t-15.74)}{2.162^{2}}}+0.3471 e^{\frac{-(t-8.846)}{2.021^{2}}}
$$

where ' $P(t)^{\prime}$ is the solar power at time ' $t$ ' of the day. The system's efficiencies were plotted against time as shown in Figure 5.

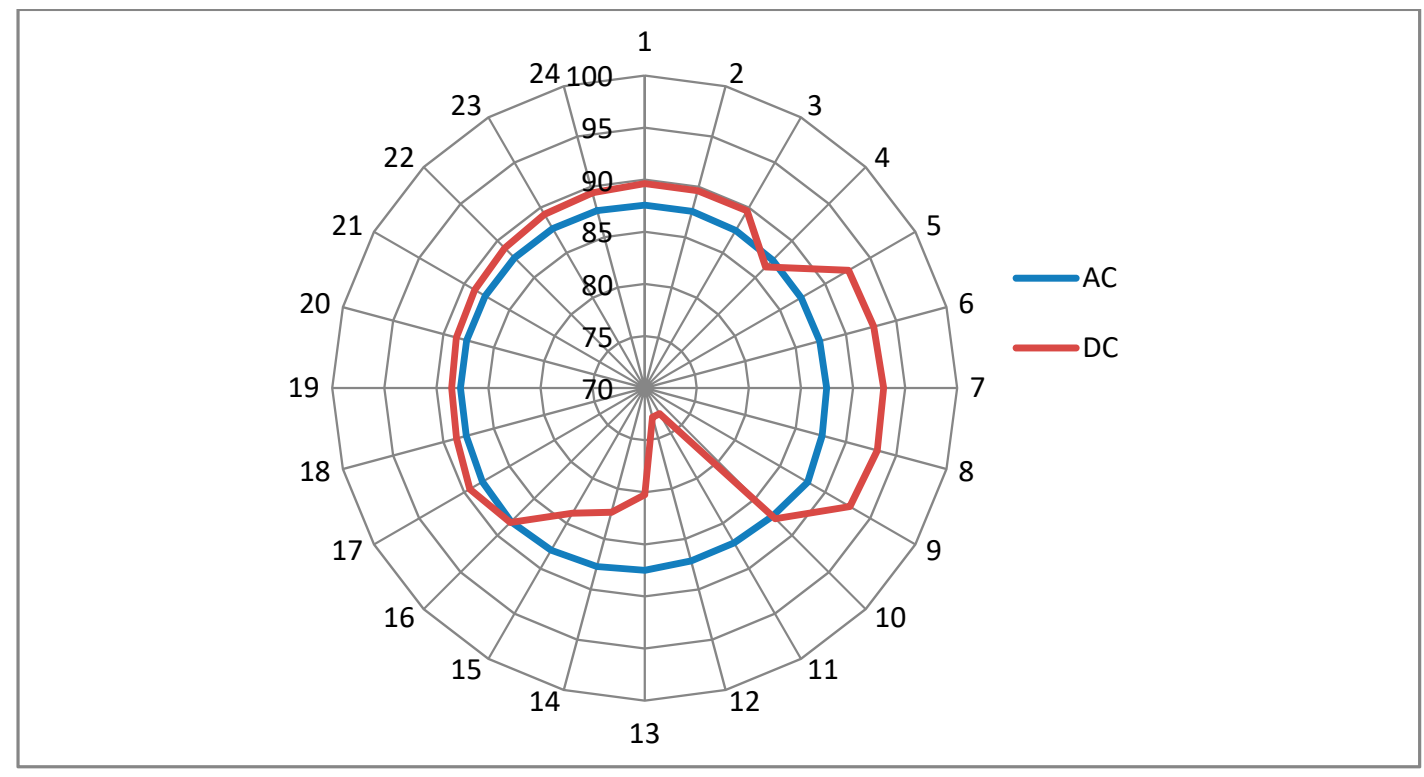

Figure 5. AC-DC system efficiency with the inclusion of 1-kW solar PV panels.

\subsection{Important Points from Efficiency Plot}

- Average efficiency

The average efficiency of the DC system with solar addition came out to be $87.5 \%$ compared to that of the AC system at $87.6 \%$. However, the DC system efficiency varies between $72.9 \%$ and $93.1 \%$, whereas the AC system efficiency is almost constant around $87 \%$. However, average efficiencies of both the systems are comparable. Although it is believed that solar PV, being a DC generating module, supports DC distribution system, the picture changes as compared to what is expected when the effect of conversion efficiencies of involved power electronic converters is included.

- Fall of the DC efficiency at 11 th and 12 th hour

' $\mathrm{D}$ ' and ' $\mathrm{I}$ ' category loads are supplied from solar panels, and the solar irradiance is at its peak. The DC grid has to supply A category loads only, which are already operating at the reduced loading. The inverters' efficiencies, which are quite low, define the system's efficiency during this interval. 
In order to check the variation in system's efficiency with solar capacity, we simulated our system for different solar capacities installed in the home. The results are presented in Figure 6. The AC system's efficiency is almost unaltered, and the DC system shows variations in lower efficiency values. However, the higher values are almost constant. The fall in efficiency lies in that with increasing solar power, more ' $\mathrm{D}$ ' type loads are driven by solar, which leaves a lower load on the DC-DC converters, driving their operating efficiencies to lower values.
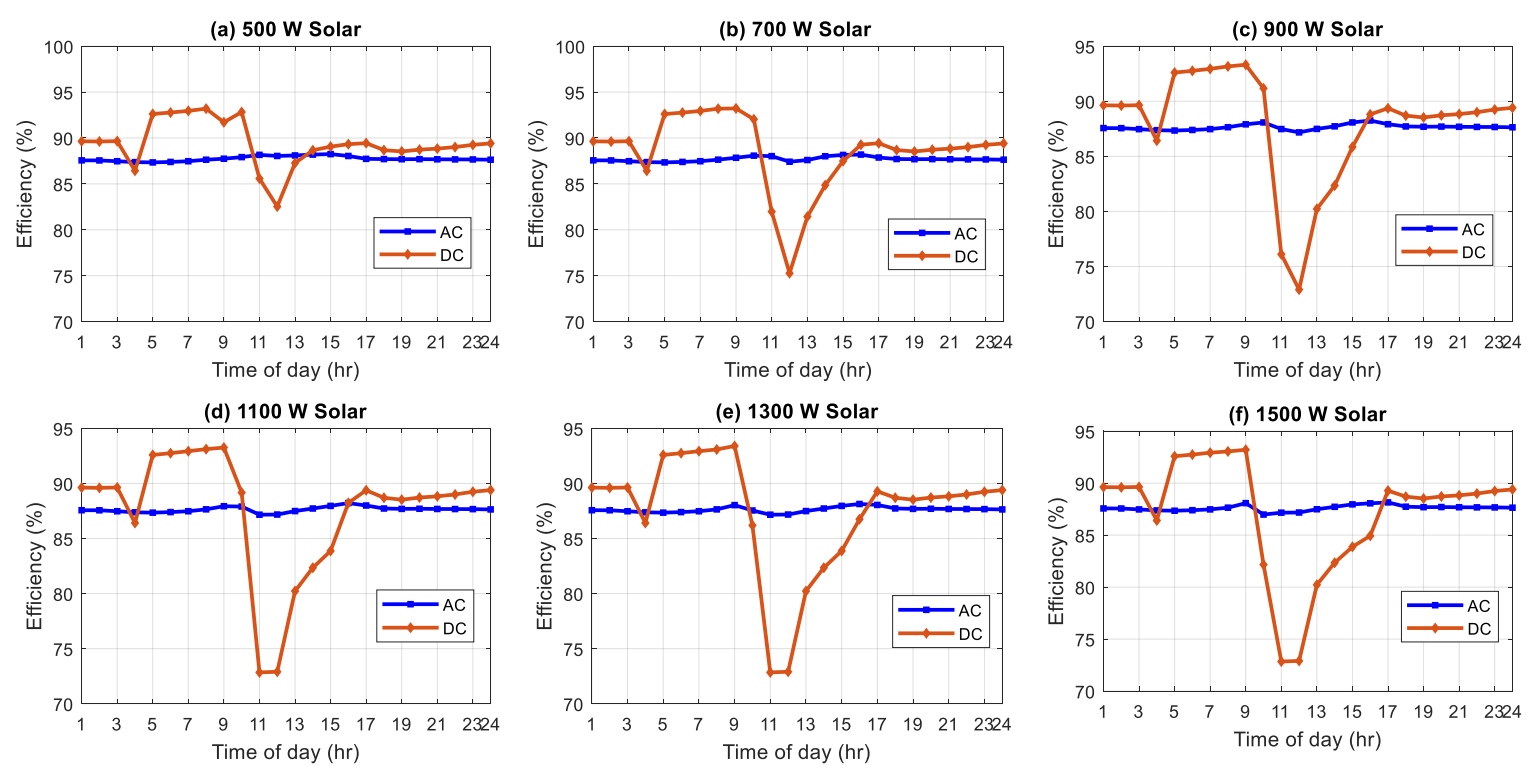

Figure 6. AC vs. DC system efficiency with varying solar capacity: (a) $500 \mathrm{~W}$, (b) $700 \mathrm{~W}$, (c) $900 \mathrm{~W}$, (d) $1100 \mathrm{~W},(\mathbf{e}) 1300 \mathrm{~W}$, and (f) $1500 \mathrm{~W}$.

\section{Overall Assessment}

The AC system efficiency is almost constant throughout the day; however, with solar PV panels installed, there are periods when D and I category loads are completely supplied by solar or battery

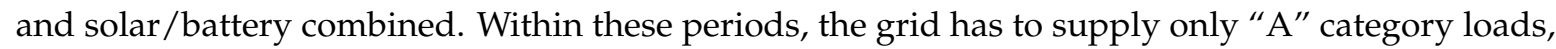
which inside the building, require no converter stage, and in-building "conversion" efficiency is almost $100 \%$. The dominant element that defines the system's efficiency is the transformer efficiency; other parameters that fractionally affect the system's efficiency are conductor losses and power factor. There is a tiny fall of the efficiency for the AC system during the 6th hour, which is due to the reduced loading within the building. The combined effect of 21 buildings per transformer poses a fall in transformer operating efficiency because the transformer is operating at a reduced efficiency to some extent.

Interpretation of results reveals that the AC system efficiency remains almost constant throughout the day, although the DC system efficiency changes with time. Due to the addition of a solar PV system, one may expect a rise in the DC efficiency, but that is not true! There are even instances when the system's efficiency is poor (as discussed for the 11th and 12th hour). The converters' loading is the most critical factor in defining the system's efficiency. While the converters are loaded close to their rating in those cases, the operating efficiency and in turn the system's efficiency are better than the case when converters are lightly loaded.

\section{Conclusions}

This research effort presented a comparative effectiveness study of AC and DC distribution systems. DC, which was considered to have become obsolete, is striking back in power systems. The battle of currents has reignited and DC has appeared in generation, transmission, distribution, 
and utilization. DC power at the distribution level is under research, and particularly the residential distribution system has become a topic of interest where AC and DC distribution systems' efficiencies are noticed to be comparable. However, this does not support DC to take AC's place at the distribution level. In order to do so, DC has to defeat AC considering all factors that affect their efficiencies. One of those factors is the daily load variation. Load variation holds a concrete footing in defining AC and DC systems' efficiency at the distribution level, as presented in this paper. With varying power consumption, the efficiencies of installed power electronic converters change, and hence, we obtain variable efficiency values of the systems. The results presented comparable overall efficiencies for AC and DC systems in this paper. However, during $24 \mathrm{~h}$, there were intervals when DC was efficient as compared to AC due to better converter efficiencies because of high converter loading. In contrast, there were periods during the day when DC showed less efficiency as compared to AC due to low converter efficiency because of reduced power consumption. The AC system efficiency remained almost constant throughout the day, whereas the DC system efficiency kept dwindling up and down. In addition, the trend of energy generation is shifting to renewable energy resources, and thus we introduced residential solar PV installations because of their rising importance. Since this research focuses on time-based analysis, we performed an analysis of time-varying solar insolation amalgamated with load variations in this paper. In addition to the solar power variations, the power capacities of solar PV panels installed in residences were also varied for analysis. Again, the results demonstrated almost the same average efficiencies for the DC and AC systems and the strong dependence of AC and DC systems' efficiency on converter efficiencies, which in turn depend on load consumption that varies with time. Hence, time is one strong factor that defines the efficiencies of both systems. Although AC and DC system efficiencies are equivalent when averaged over $24 \mathrm{~h}$, for DC, to completely wipe AC out of the distribution sector, DC should overcome AC throughout the day.

Author Contributions: H.E.G., Conceptualization, Data curation, Investigation, Methodology, Validation, Writing-original draft; F.D., Project administration, Supervision, Writing-review, editing; K.S., Investigation, Methodology, Validation, Writing—review; M.N., Conceptualization, Investigation, Methodology, Writing—review, editing; K.A.K.N., Writing—review, editing; Y.Y., Writing—review, editing.

Funding: This research received no external funding.

Acknowledgments: Special thanks to Muhammad Umair and Amber Rasheed for their support.

Conflicts of Interest: The authors declare no conflict of interest.

\section{Appendix A}

Hourly power consumptions of 'A', 'D' and 'I' category shown in Table 2 are presented here graphically in Figure A1.

The loading of DC-AC converters and DC-DC converters are the decisive factors in the system's efficiency. Figure A2 shows that the building efficiency of the AC home is almost constant, whereas the DC home efficiency varies due to a varying load, hence converter efficiencies. In the case of the $\mathrm{AC}$ home, converters are required for ' $\mathrm{D}$ ' category loads only; ' $\mathrm{A}$ ' and ' $\mathrm{I}$ ' category loads require no converter for their operation. Moreover, there is no significant drop/rise in the power consumption of ' $\mathrm{D}$ ' category loads, which may cause notable efficiency variation of the AC-DC converter, making the overall building efficiency almost constant. For most of the day, the DC home's efficiency is better than the AC home except during the 4th, 11th and 12th hours. During the 4th hour, there is a significant drop in the consumption of space cooling and refrigeration, due to which the installed inverters operate at a lower efficiency. In addition, during the 11th and 12th hours, the space cooling is again operating at low power, thereby affecting inverter's efficiency. Since the DC home's efficiency curve is above the AC home for more than $85 \%$ of the day, the average efficiency of the DC home is $93.2 \%$, whereas for AC home it is $90.0 \%$. 
(a) 'A' category loads power consumption

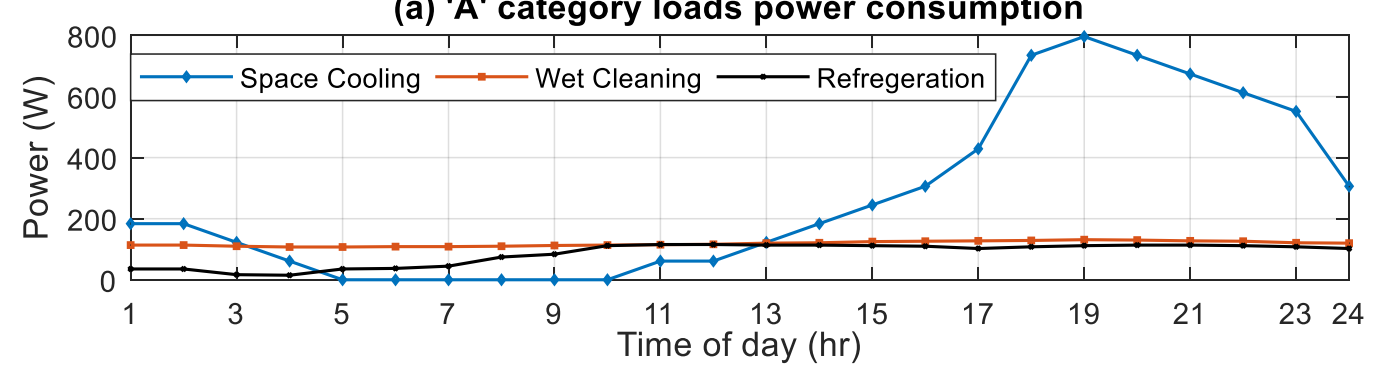

(b) 'D' category loads power consumption

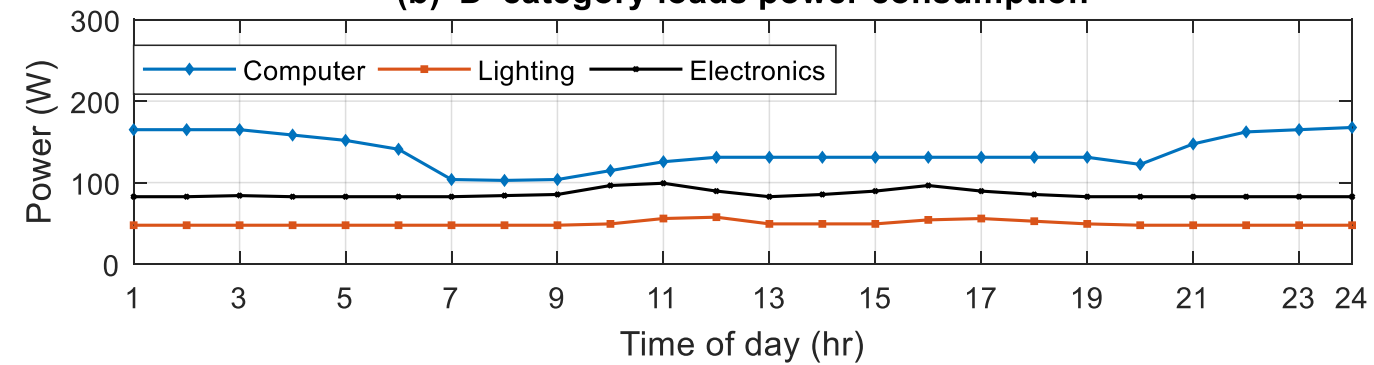

(c) 'l' category loads power consumption

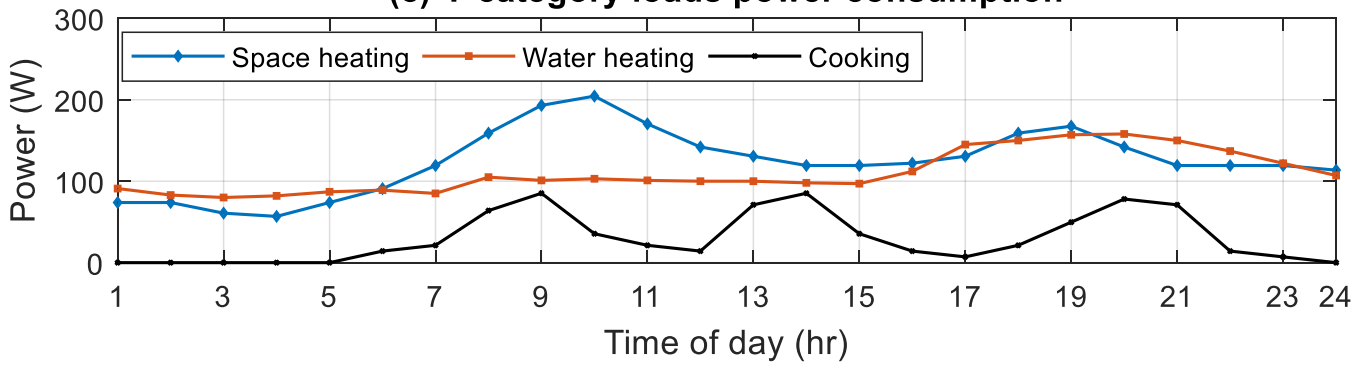

Figure A1. Hourly power consumption under different load categories: (a) 'A' category loads, (b) 'D' category loads, and (c) 'I' category loads.

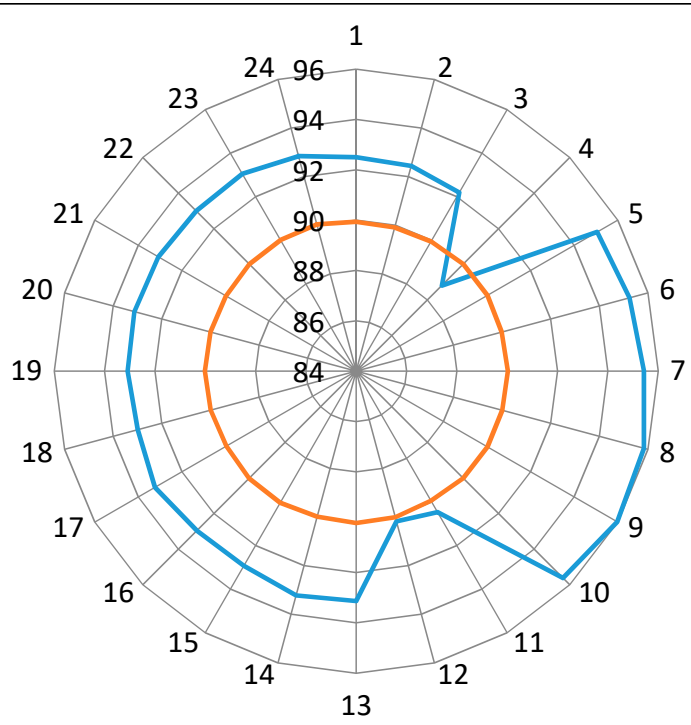

Figure A2. Building efficiencies when adopting the AC or DC systems. 


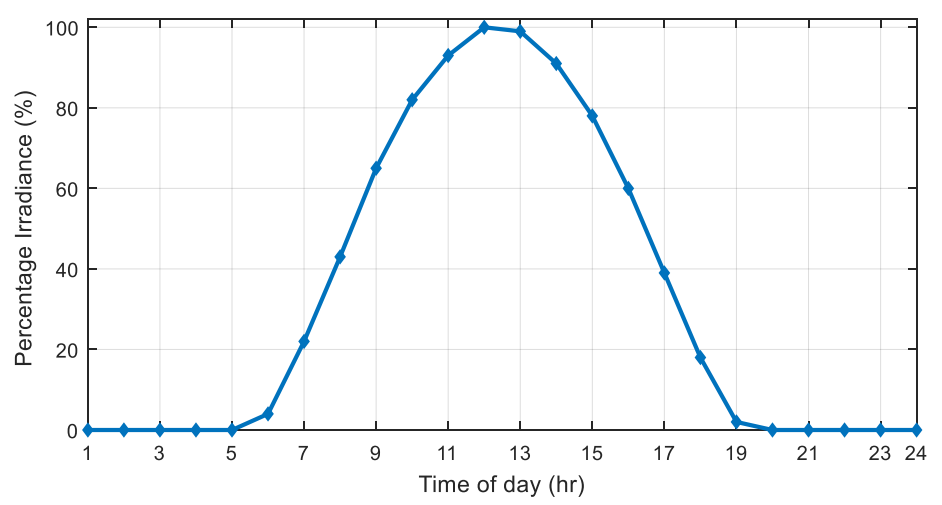

Figure A3. Solar insolation curve [38].

\section{References}

1. Sulzberger, C.L. Triumph of AC-from Pearl Street to Niagara. IEEE Power Energy Mag. 2003, 99, 64-67. [CrossRef]

2. Sulzberger, C.L. Triumph of AC. 2. The battle of the currents. IEEE Power Energy Mag. 2003, 1, 70-73. [CrossRef]

3. Nordman, B.; Christensen, K. DC local power distribution: technology, deployment, and pathways to success. IEEE Electron. Mag. 2016, 4, 29-36. [CrossRef]

4. Rudervall, R.; Charpentier, K.; Sharma, R. High Voltage Direct Current (HVDC) Transmission Systems Technology Review Paper. In Proceedings of the Energy Week 2000, Washington, DC, USA, 7-8 March 2000.

5. Siraj, K.; Siraj, H.; Nasir, M. Modeling and control of a doubly fed induction generator for grid integrated wind turbine. In Proceedings of the 16th IEEE Power Electronics and Motion Control Conference and Exposition, Antalya, Turkey, 21-24 September 2014.

6. Chen, Z.; Guerrero, J.M.; Blaabjerg, F. A review of the state of the art of power electronics for wind turbines. IEEE Trans. Power Electron. 2009, 24, 1859-1875. [CrossRef]

7. Blaabjerg, F.; Liserre, M.; Ma, K. Power electronics converters for wind turbine systems. IEEE Trans. Ind. Appl. 2012, 48, 708-719. [CrossRef]

8. Dastgeer, F.; Gelani, H.E. A Comparative analysis of system efficiency for AC and DC residential power distribution paradigms. Energy Build. 2017, 138, 648-654. [CrossRef]

9. Nasir, M.; Khan, H.A.; Zaffar, N.A.; Vasquez, J.C.; Guerrero, J.M. Scalable Solar DC Micrigrids: On the Path to Revolutionizing the Electrification Architecture of Developing Communities. IEEE Electron. Mag. 2018, 6, 63-72. [CrossRef]

10. Nasir, M.; Iqbal, S.; Khan, H.A. Optimal planning and design of low-voltage low-power solar DC microgrids. IEEE Trans. Power Syst. 2018, 33, 2919-2928. [CrossRef]

11. Nasir, M.; Jin, Z.; Khan, H.A.; Zaffar, N.A.; Vasquez, J.C.; Guerrero, J.M. A decentralized control architecture applied to DC nanogrid clusters for rural electrification in developing regions. IEEE Trans. Power Electron. 2018, 2, 1773-1785. [CrossRef]

12. Nasir, M.; Khan, H.A.; Niazi, K.A.K.; Jin, Z.; Guerrero, J.M. Dual-loop Control Strategy applied to PV/battery based Islanded DC microgrids for Swarm Electrification of Developing Regions. J. Eng. 2018, in press.

13. Nasir, M.; Khan, H.A.; Hussain, A.; Mateen, L.; Zaffar, N.A. Solar PV-based scalable DC microgrid for rural electrification in developing regions. IEEE Trans. Sustain. Energy 2018, 9, 390-399. [CrossRef]

14. Hamza, M.; Shehroz, M.; Fazal, S.; Nasir, M.; Khan, H.A. Design and Analysis of Solar PV Based Low-Power Low-voltage DC Microgrid Architectures for Rural Electrification. In Proceedings of the IEEE Power \& Energy Society General Meeting, Chicage, IL, USA, 16-20 July 2017.

15. Tefferi, M.; Li, Z.; Uehara, H.; Chen, Q.; Cao, Y. Characterization of Space Charge and DC Field Distribution in XLPE and EPR During Voltage Polarity Reversal with Thermal Gradient. In Proceedings of the Electrical Insulation and Dielectric Phenomenon, Fort Worth, TX, USA, 22-25 October 2017.

16. Augustine, S.; Quiroz, J.E.; Reno, M.J.; Brahma, S. DC Microgrid Protection: Review and Challenges; Sandia National Lab: Albuquerque, NM, USA, 2018.

17. Cavanagh, K.; Belk, J.A.; Turitsyn, K. Transient stability guarantees for ad hoc DC microgrids. IEEE Control Syst. Lett. 2018, 2, 139-144. [CrossRef] 
18. Pratt, A.; Kumar, P.; Aldridge, T.V. Evaluation of 400V DC distribution in telco and data centers to improve energy efficiency. In Proceedings of the 29th IEEE International Telecommunications Energy Conference, Rome, Italy, 30 September-4 October 2007.

19. Becker, D.J.; Sonnenberg, B. DC Microgrids in Buildings and Data Centers. In Proceedings of the 33rd IEEE International Telecommunications Energy Conference, Amsterdam, The Netherlands, 9-13 October 2011.

20. Amin, M.; Arafat, Y.; Lundberg, S.; Mangold, S. Low Voltage DC Distribution System Compared with 230 V AC. In Proceedings of the IEEE Electrical Power and Energy Conference, Winnipeg, MB, Canada, 3-5 October 2011.

21. Fregosi, D.; Ravula, S.; Brhlik, D.; Saussele, J.; Frank, S.; Bonnema, E.; Scheib, J.; Wilson, E. A Comparative Study of DC and AC microgrids in Commercial Buildings across Different Climates and Operating Profiles. In Proceedings of the 1st IEEE International Conference on DC Microgrids, Atlanta, GA, USA, 7-10 June 2015.

22. Hammerstrom, D.J. AC Versus DC Distribution Systems Did We Get It Right? In Proceedings of the IEEE Power Engineering Society General Meeting, Tampa, FL, USA, 24-28 June 2007.

23. Starke, M.; Tolbert, L.M.; Ozpineci, B. AC vs. DC Distribution: A Loss Comparison. In Proceedings of the IEEE Transmission and Distribution Conference and Exposition, Chicago, IL, USA, 21-24 April 2008.

24. Dastgeer, F.; Gelani, H.E.; Anees, H.M.; Paracha, Z.J.; Kalam, A. Analyses of efficiency/energy-savings of DC power distribution systems/microgrids: Past, present and future. Int. J. Electr. Power Energy Syst. 2019, 104, 89-100. [CrossRef]

25. Fairley, P. DC versus AC: The second war of currents has already begun [in my view]. IEEE Power Energy Mag. 2012, 10, 104. [CrossRef]

26. Han, J.; Oh, Y.S.; Gwon, G.H.; Kim, D.U.; Noh, C.H.; Jung, T.H.; Lee, S.J.; Kim, C.H. Modeling and analysis of a low-voltage de distribution system. Resources 2015, 4, 713-735. [CrossRef]

27. Ryu, M.H.; Kim, H.S.; Baek, J.W.; Kim, H.G.; Jung, J.H. Effective test bed of 380-V DC distribution system using isolated power converters. IEEE Trans. Ind. Electron. 2015, 62, 4525-4536. [CrossRef]

28. Sannino, A.; Postiglione, G.; Bollen, M.H. Feasibility of A DC Network for Commercial Facilities. In Proceedings of the IEEE Industry Applications Conference, Pittsburgh, PA, USA, 13-18 October 2002.

29. Vossos, V.; Garbesi, K.; Shen, H. Energy savings from direct-DC in US residential buildings. Energy Build. 2014, 68, 223-231. [CrossRef]

30. Gelani, H.E.; Dastgeer, F. Efficiency analyses of a DC residential power distribution system for the modern home. Adv. Electr. Comput. Eng. 2015, 15, 135-142. [CrossRef]

31. Dastgeer, F.; Kalam, A. Efficiency comparison of DC and AC distribution systems for distributed generation. In Proceedings of the IEEE Power Engineering Conference, Adelaide, Australia, 27-30 September 2009.

32. Residential Energy Consumption Survey. 2016. Available online: https://www.eia.gov/consumption/ residential/data/2015/ (accessed on 8 January 2019).

33. Energy Administration Residential Data. Available online: www.eia.gov/consumption/residential/data (accessed on 8 January 2019).

34. Fan, H.; Li, H. High-frequency transformer isolated bidirectional DC-DC converter modules with high efficiency over wide load range for $20 \mathrm{kVA}$ solid-state transformer. IEEE Trans. Power Electron. 2011, 26, 3599-3608. [CrossRef]

35. Kim, H.S.; Ryu, M.H.; Baek, J.W.; Jung, J.H. High-efficiency isolated bidirectional AC-DC converter for a DC distribution system. IEEE Trans. Power Electron. 2013, 28, 1642-1654. [CrossRef]

36. Scarabelot, L.T.; Rambo, C.R.; Rampinelli, G.A. A relative power-based adaptive hybrid model for DC/AC average inverter efficiency of photovoltaics systems. Renew. Sustain. Energy Rev. 2018, 92, 470-477. [CrossRef]

37. Feil, D.L.P.; Silva, P.R.; Bernardon, D.P.; Marchesan, T.B.; Sperandio, M.; Medeiros, L.H. Development of an efficient distribution transformer using amorphous core and vegetable insulating oil. Electr. Power Syst. Res. 2017, 144, 268-279. [CrossRef]

38. Solar Resource Data and Tools, National Renewable Energy Laboratory (NREL). Available online: https: / / www.nrel.gov/grid/solar-resource/renewable-resource-data.html (accessed on 9 January 2019).

(C) 2019 by the authors. Licensee MDPI, Basel, Switzerland. This article is an open access article distributed under the terms and conditions of the Creative Commons Attribution (CC BY) license (http:/ / creativecommons.org/licenses/by/4.0/). 